Factor XIII

fibrin-stabilizing factor maternal hemorrhage newborn placenta premature respiratory distress syndrome

\title{
Changes in Fibrin-stabilizing Factor Levels in Relation to Maternal Hemorrhage and Neonatal Disease
}

\author{
G. M.Ambrus ${ }^{[53]}$, J.L.Ambrus, K. R. Niswander, D. H.Weintraub, I.D.J. Bross and \\ H. B. LASSMAN \\ Roswell Park Memorial Institute and Departments of Pediatrics, Medicine, \\ and Gynecology-Obstetrics, School of Medicine, State University of New York at Buffalo, Buffalo, \\ New York, USA
}

\section{Extract}

An increase of several clotting factors and fibrinolytic inhibitors was reported to occur during pregnancy, following delivery and surgery. In the present study, it was found that fibrin-stabilizing factor (factor XIII, FSF) increased after delivery. Following hemorrhage during pregnancy, FSF was increased when the bleeding episode was 'mild', but after moderate to severe bleeding FSF was lower than normal. In the case of 'mild' bleeding episodes there was usually a greater time lapse between inception of hemorrhage and delivery, allowing for a compensatory rise in clotting factors.

The levels of FSF were increased in newborn infants experiencing respiratory distress syndrome (RDS). Correlation was found between levels of FSF in mothers and offspring. Transplacental passage of FSF (or a factor regulating FSF synthesis) may explain the relationship between bleeding episodes in the mother and RDS in the infant, a relationship demonstrated previously through the use of epidemiologic methods.

\section{Speculation}

Mild but long-lasting bleeding during pregnancy may result in a compensatory increase in clotting factors including FSF. Transplacental passage of FSF, or of a factor regulating FSF synthesis, into the newborn may result in increased resistance of intraalveolar fibrin deposits to the natural course of fibrinolysis. This phenomenon may explain the high incidence of respiratory distress due to hyaline membrane disease in infants born from mothers with hemorrhagic complications of pregnancy.

\section{Introduction}

The prevalence of respiratory distress syndrome (RDS) in premature infants is well known [7]. Correlation has been shown to exist between bleeding episodes of the mother during pregnancy and the presence of pulmonary hyaline membranes at autopsy in infants who succumbed to RDS [10]. In most instances, women with antepartum hemorrhage deliver before term [14, 35]; it is difficult, therefore, to separate the role of hemorrhage in producing prematurity, from hemorrhage itself as an etiological factor in the development of pulmonary hyaline membranes.

It is well documented that the levels of several clotting factors increase during the course of pregnancy $[3,8,33,45]$. Increased levels of some factors of the blood coagulation and of the fibrinolysin systems have also been shown to occur after delivery [12] and following surgery $[12,15,37,46]$. At this time, pulmonary hyaline membranes are considered to be basically clots 
formed subsequent to effusion of plasma from the pulmonary circulation into the alveolar spaces $[17,18$, 49]. Thus, the level of circulating factors of the blood coagulation and fibrinolysin systems could have a decisive role in determining the fate of the alveolar hyaline membranes.

Deficiencies in certain components of the fibrinolysin system in premature infants have been reported $[5,6$, $33,39,43$ ], and the hypothesis was presented that such deficiencies may contribute to the high incidence of RDS in premature infants. In the present study, we have analyzed the level of fibrin-stabilizing factor (FSF), also known as the Laki-Lorand factor [26] or factor XIII, in various groups of newborns, in women after normal delivery, and in women with hemorrhagic complications of pregnancy, in an attempt to find a correlation between RDS in the infants and bleeding in the mothers. Informed consent was obtained from the subjects or their parents.

\section{Materials and Methods}

In women, blood samples were obtained from the antecubital vein and in newborns, from the umbilical vein; hemorepellent needles and siliconized syringes containing $3.8 \%$ sodium citrate $(1 \mathrm{ml}$ with $9 \mathrm{ml}$ of blood) were used. The blood was kept cold $\left(4^{\circ}\right)$ until the plasma wasseparated in a refrigerated centrifuge. Whenever possible, the plasma was immediately worked up. If this was not feasible, the samples were frozen and kept at $-20^{\circ}$ until the biochemical assays could be performed.

In preliminary experiments, triplicate samples determined before and after freezing at $-20^{\circ}$ showed the same FSF titers.

The samples were worked up in the order of collection.

The reagents used for the FSF assay included human fibrinogen and human thrombin [50], both purified according to the method of Hink and MaDonald [21]. The same batches of reagents were used throughout the experiment. Cysteine solutions were always freshly prepared before the assay. Imidazole buffer, $0.05 \mathrm{M}$, $\mathrm{pH} 7.4$, was used as a diluent.

The method used for the determination of FSF was based on the principle that clots devoid of FSF are soluble in $1 \%$ monochloracetic acid $[29,41]$. A twofold dilution series (up to $1: 128$ ) of plasma was prepared; $0.1 \mathrm{ml}$ of each dilution was mixed with $0.1 \mathrm{ml}$ of $0.02 \mathrm{M}$ cysteine and incubated at $28^{\circ}$ for $10 \mathrm{~min}$ to accomplish activation of FSF in the plasma [31]. A clot was formed at $37^{\circ}$ in a $13-\mathrm{mm}$ by $100-\mathrm{mm}$ glass tube containing $0.4 \mathrm{ml}$ of $0.6 \%$ fibrinogen, $0.1 \mathrm{ml}$ thrombin solution (25 NIH units), $0.1 \mathrm{ml}$ of $0.2 \mathrm{~mm}$ $\mathrm{CaCl}_{2}$, and $0.2 \mathrm{ml}$ preincubated cysteine-plasma mix- ture. Control clots contained a mixture of cysteine and imidazole buffer, $0.05 \mathrm{M}, \mathrm{pH} 7.4$, instead of plasma. One-half hour after the clot was formed, $0.8 \mathrm{ml}$ of $1.4 \%$ monochloracetic acid was layered over it. The test tube was kept at $37^{\circ}$ and the presence of the clot was checked at 10-min intervals. Control clots dissolved completely in $40 \mathrm{~min}$. The FSF titer of the plasma sample was defined as the highest dilution at which the clot was still visible at $60 \mathrm{~min}$.

In preliminary studies, triplicate determinations showed strict agreement in the FSF titers in all instances; therefore, in the experimental samples, single determinations were considered acceptable.

Fibrinogen and thrombin were tested for FSF contamination in the following way. In a series of control clots containing buffer instead of plasma, the concentration of cysteine was varied from 0.01 to $0.5 \mathrm{M}$, and dissolution of the clot was determined as has just been described. The concentration of cysteine did not change the dissolution time; consequently, we have accepted the reagents as being free of FSF contamination and thus suitable for the assay.

Ideally, plasma should be preincubated with thrombin to activate the FSF contained therein [29]. Because this was not feasible, the concentration of thrombin was in excess of that needed for clotting, so as to achieve immediate activation of FSF at the time of mixing. All titers reported refer to activated FSF. We have not attempted to measure the inactive form of this enzyme. During the course of clot formation, whether in vivo or in vitro, thrombin not only converted fibrinogen to fibrin, but simultaneously activated plasma FSF as it was incorporated into the clot. Thus, under the conditions of our assay, the measurement of inactive FSF would be meaningless.

We have questioned whether the level of fibrinogen may have influenced the FSF titers as determined by our method. Therefore, we measured fibrinogen levels

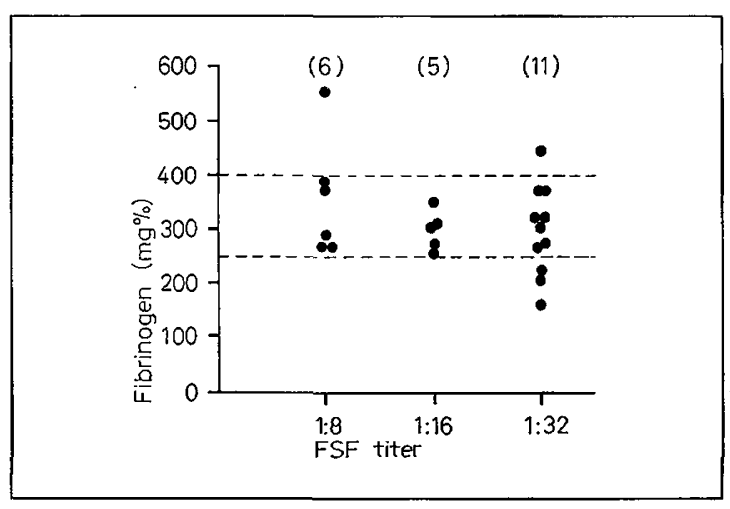

Fig. 1. Plasma fibrin-stabilizing factor (FSF) titers versus levels of fibrinogen (samples from 22 women). 
in the first 22 samples. Figure 1 shows that except for five samples, all values of fibrinogen fell within 250-400 $\mathrm{mg} / 100 \mathrm{ml}$, which was considered the normal range in our laboratory. Correlation of FSF titers with the level of fibrinogen could not be established.

\section{Results}

Titers of FSF were determined in three different groups of newborns: a) healthy mature infants; $b$ ) healthy premature infants; and $c$ ) infants with RDS. The criterion for prematurity was a birth weight of $2.5 \mathrm{~kg}$ or less. Five of the healthy premature infants had birth weights ranging from 1.6 to $1.9 \mathrm{~kg}$, the birth weights of four others fell between 2-2.4 kg. Titers of FSF in the three groups are shown in table $\mathrm{I}$; the same data were projected on a distribution curve in figure 2 . For the two larger series, the RDS infants and the healthy mature infants, the distributions were roughly Gaussian. The number of normal premature infants was too small to give a clear picture of the distribution, but it appeared to be a mixture of the other two groups. In normal babies, a 1:8 titer occurred with the greatest frequency: in $50 \%$ of the mature infants and in $56 \%$ of

Table I. Titers of fibrin-stabilizing factor (FSF) in various groups of newborn infants

\begin{tabular}{lccc}
\hline Titer & \multicolumn{3}{c}{ Infants } \\
\cline { 2 - 4 } & $\begin{array}{c}\text { No. of } \\
\text { healthy } \\
\text { mature }\end{array}$ & $\begin{array}{c}\text { No. of } \\
\text { healthy } \\
\text { premature }\end{array}$ & $\begin{array}{c}\text { No. with } \\
\text { RDS }\end{array}$ \\
\hline $1: 4$ & 6 & 0 & 0 \\
$1: 8$ & 17 & 5 & 3 \\
$1: 16$ & 9 & 2 & 22 \\
$1: 32$ & 2 & 2 & 6 \\
Total & 34 & 9 & 31 \\
\hline
\end{tabular}

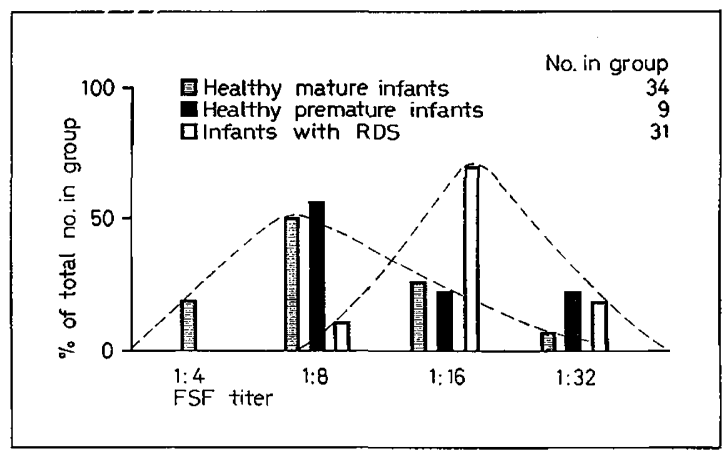

Fig. 2. Titers of fibrin-stabilizing factor (FSF) in various groups of newborn infants. the premature infants. A titer of $1: 4$ occurred in 6 of 34 mature infants. Among the infants with RDS, a titer of $1: 16$ appeared most frequently, indicating a 'shift to the right' compared with the titer of normal infants. The number of infants with a higher FSF titer $(1: 32)$ was also greater in the RDS group (19\%) than in normal mature infants $(6 \%)$. Statistical analysis with the Wilcoxon method [44] showed a significant difference at the $1 \%$ level between the FSF titers of the normal and the RDS group. Corresponding Wilcoxon tests for normal premature infants versus normal mature infants and versus RDS babies did not give statistically significant results at the $5 \%$ level. With only nine normal premature babies and considerable overlapping of the distributions, it would not be expected that standard statistical methods would show clearcut differences between the normal premature babies and the other groups. In none of these groups was there correlation between birth weight and FSF titers.

Figure 3 shows the distribution of FSF titers in a) women with bleeding complications in the last trimester of pregnancy, compared with b) healthy, pregnant women in the same trimester, and $c$ ) healthy, nonpregnant women. All 10 healthy, nonpregnant individuals had an FSF titer of $1: 16$. Among the 13 healthy, expectant women the majority $(62 \%)$ had titers of $1: 16,31 \%$ had titers of $1: 8$, and $7 \%$ had titers of $1: 32$. In contrast, in women with prenatal bleeding complications, few women had titers of $1: 16(19 \%)$; most showed titers divided between 1:8 (39\%) and $1: 32(42 \%)$. Thus, the distribution pattern shown by these women seems to be U-shaped or bimodal. This kind of bimodality tends to occur when nonhomogeneous patients are put into the same series.

In an attempt to distinguish possible subgroups in the series of women with bleeding complications, the individual donors were examined to see if there was

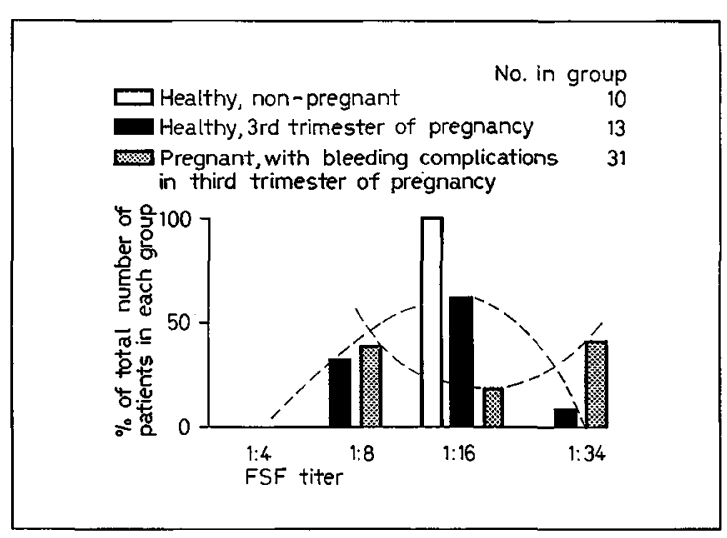

Fig. 3. Titers of fibrin-stabilizing factor (FSF) in various groups of women. 
any relation between the etiology or severity of the prenatal bleeding episode and the FSF level.

Table II shows that the cause of prenatal bleeding among 31 women was abruptio placentae in $20(64 \%)$, placenta previa in $4(13 \%)$, and unclassified in $7(23 \%)$. The distribution of FSF titers within these groups did not seem to follow a pattern.

In table III, FSF titers are correlated with the severity of the bleeding episode. Subdivision into mild, moderate, and severe, follows the classification accepted in obstetrics for abruptio placentae $(13,19,35)$, which takes into consideration the general condition of the patient (shock, uterine consistency), in addition to the degree of bleeding.

In $11(58 \%)$ of 19 patients, in whom the bleeding episode was classified as mild, the FSF titers were high $(1: 32)$. In $8(67 \%)$ of 12 patients with moderate or severe bleeding episodes, the FSF titers were low $(1: 8)$. Although the number of patients in these groups was small, the trend of the distribution suggests that the FSF titer may be related to the severity of the bleeding episode. Statistical analysis indicated a significant difference at the $5 \%$ level between the two subgroups (women with hemorrhages) with regard to FSF levels.

Since every normal delivery is accompanied by some degree of blood loss, it was of interest to study FSF

Table II. Correlation of titers of FSF in 31 mothers (hemorrhagic) with etiology of bleeding

\begin{tabular}{|c|c|c|c|c|}
\hline \multirow{2}{*}{$\begin{array}{l}\text { Cause of } \\
\text { bleeding }\end{array}$} & \multirow{2}{*}{$\begin{array}{l}\text { No. of } \\
\text { mothers } \\
\text { with com- } \\
\text { plications }\end{array}$} & \multicolumn{3}{|c|}{ Titer } \\
\hline & & $1: 8$ & $1: 16$ & $1: 32$ \\
\hline $\begin{array}{l}\text { Abruptio } \\
\text { placentae }\end{array}$ & 20 & 9 & 4 & 7 \\
\hline Placentae previa & 4 & 2 & 1 & 1 \\
\hline Unclassified & 7 & 1 & 1 & 5 \\
\hline Total & 31 & 12 & 6 & 13 \\
\hline
\end{tabular}

Table III. Correlation of titers of FSF in hemorrhagic mothers with severity of symptoms

\begin{tabular}{lcccc}
\hline Severity & $\begin{array}{c}\text { No. of } \\
\text { mothers }\end{array}$ & \multicolumn{3}{c}{ Titer } \\
\cline { 3 - 5 } $\begin{array}{c}\text { with com- } \\
\text { plications }\end{array}$ & $1: 8$ & $1: 16$ & $1: 32$ \\
\hline Mild & 19 & 4 & 4 & 11 \\
$\begin{array}{l}\text { Moderate and } \\
\text { severe }\end{array}$ & 12 & 8 & 2 & 2 \\
Total & 31 & 12 & 6 & 13 \\
\hline
\end{tabular}

levels in women who did not experience hemorrhagic complications immediately after delivery, and a few days later, before discharge from the hospital. Figure 4 shows a difference between these two groups in the frequency distribution of FSF titers. When blood was collected in the delivery room, the FSF titer in the majority of patients was 1:8. Two-to-four days after delivery the maximum frequency had shifted to a titer of $1: 16$, the same as was found in the group of normal nonpregnant women (fig. 3).

This difference, however, was not found to be statistically significant. This shift may be interpreted as a compensatory response following blood loss in the course of delivery, but it could also be a reflection of fibrinolytic activity during delivery [40], which may work in opposition to the effect of FSF, with subsequent return toward normal titers shown before pregnancy.

Because FSF titers of 1:32 (the highest found in this study) occurred most commonly in women with mild bleeding complications (table III), and in infants with RDS (fig. 2), we speculated that FSF titers of mother and offspring might be correlated. In 31 deliveries, paired blood samples were obtained from the antecubital vein of the mother and the cord of the infant. Titers of FSF in these paired samples are shown in table IV. A statistically significant correlation was

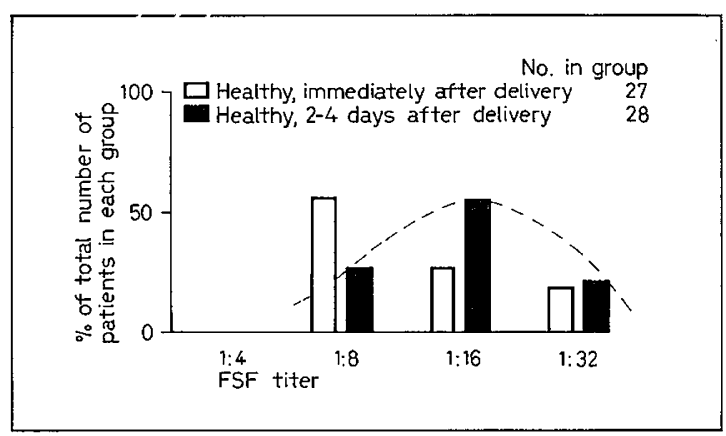

Fig. 4. Titers of fibrin-stabilizing factor (FSF) in various groups of women after delivery.

Table IV. Correlation of titers of FSF in mothers and in cord blood (no. of patients)

\begin{tabular}{|c|c|c|c|c|c|}
\hline \multirow{2}{*}{$\begin{array}{l}\text { Cord, } \\
\text { titer }\end{array}$} & \multicolumn{4}{|c|}{ Mother, titer } & \multirow[t]{2}{*}{ Total } \\
\hline & $1: 4$ & $1: 8$ & $1: 16$ & $1: 32$ & \\
\hline $1: 4$ & & 1 & & & 1 \\
\hline $1: 8$ & & 12 & 1 & & 13 \\
\hline $1: 16$ & & 2 & 8 & & 10 \\
\hline $1: 32$ & & 0 & 1 & 6 & 7 \\
\hline Total & & 15 & 10 & 6 & 31 \\
\hline \multicolumn{6}{|c|}{$\chi^{2}=41.8777 ; P<0.01$} \\
\hline
\end{tabular}


found to exist between the FSF titers of mothers and their infants. Whether this was the result of transuterine passage of FSF or of a common influence on the regulatory mechanism of FSF production remains to be explored.

\section{Discussion}

Since the original discovery of FSF by LAKI and LoRAND in 1948 [26], the biological significance of this factor has been only partially unfolded. It is known that clots stabilized with FSF have an increased resistance to fibrinolysis by activators $[9,28,47,48]$, and that congenital or acquired deficiency in FSF may be accompanied by a tendency to bleeding and occasionally by severe hemorrhage [1]. No previous study, however, has dealt with the possible consequences of an increased FSF level. We have referred before to the tendency of several clotting factors to overshoot in the process of hemostatic restitution. An increase in FSF levels following low grade bleeding during pregnancy, or following delivery, could be regarded as part of this general phenomenon. We know that it is not simply a reflection of an increased fibrinogen level because no correlation was found between the levels of FSF and fibrinogen in 22 consecutive patient samples (fig. 1). This lack of correlation has also been reported by others [2].

We can provide no clear-cut explanation for the increase in FSF levels following low grade bleeding as opposed to the decrease after severe hemorrhage. Several factors can be considered, however. In a severe bleeding episode, there is little time lag between onset of bleeding and delivery [3, 45]. Many hemorrhagic patients may have developed consumption coagulopathy presenting a combination of blood clotting and fibrinolysis. In patients with mild bleeding episodes, however, usually no attempt is made to produce rapid delivery; the hemorrhage is apt to be more sustained, but with less disruption of the blood clotting and fibrinolytic mechanisms. Bleeding actually may go on simultaneously with the process of hemostatic restoration and a compensatory rise in blood clotting factors.

The increased levels of FSF in infants with RDS were unexpected, since this group of patients has a high incidence of intracranial and pulmonary hemorrhage [4]. Although most clotting factors are low at birth, an increased clotting tendency has been reported to occur in the blood of normal newborns [8], as well as in newborns with RDS [16, 22, 24, 34, 42]. Kunzer [25] noted that clots from cord blood have an increased resistance to fibrinolysis compared with those from older children, and attributed this difference to the existence of a special 'fetal' fibrinogen.

The correlation between maternal and newborn
FSF levels in our study suggests transplacental passage of either FSF or some factor regulating FSF production. The molecular size of FSF was estimated by LoRAND et al. [32] to be 156,000-195,000, and by LoEwY et al. [27] to be 350,000 , consisting of three subunits of 110,000 each. The lower figures would place FSF in the range of the 7S antibodies that have been shown to cross the placenta [19]. If this is the case, an increased FSF level in mothers with mild bleeding episodes may be transmitted to the child, born prematurely, thus contributing to the persistence of any alveolar hyaline membrane formation that may occur. Accordingly, we feel that the results of our study may help to explain at least one aspect of the relation between bleeding complications of pregnancy and RDS of infants.

After completing this manuscript a paper by CoopLAND $e t$ al. [11] came to our attention. These authors reported that FSF levels were lower in pregnant patients than in nonpregnant women. Our results show (fig. 3) that in the third trimester of pregnancy, FSF levels were distributed according to a Gaussian curve, some higher, some lower, and some in the same range as that of normal, nonpregnant women, who exhibited a remarkably uniform titer.

\section{Summary}

Infants with respiratory distress syndrome (RDS) were found to have higher levels of fibrin-stabilizing factor (FSF) than healthy infants. Healthy mothers had relatively low levels of FSF immediately after delivery, but normal-to-increased levels were found 2-4 days later. In mothers with bleeding complications of pregnancy, FSF levels were not correlated with the etiology of hemorrhage but with the degree of severity of the bleeding episode: FSF titers were higher in patients with mild bleeding episodes, but lower in patients with moderate-to-severe bleeding. The hypothesis is presented that mothers with mild bleeding episodes are placed on bed rest and are observed for a prolonged period of time, thus gaining an opportunity for a compensatory increase in FSF synthesis; mothers with severe bleeding complications, however, are delivered rapidly, and thus they may have a low level of FSF because of blood loss. In both groups, infants are delivered prematurely and have a high risk of developing respiratory distress syndrome due to hyaline membrane disease.

Statistically, significant correlation was found between FSF titers in the mother and in cord blood. Thus, an increased FSF level in a mother with previous bleeding may be transferred to a baby with a high risk for RDS, and may contribute to the persistence of alveolar hyaline membranes if they develop. 


\section{References and Notes}

1. Alami, S.Y.; Hampton, J.W.; Race, G.J. and SpeER, R.J.: Fibrin stabilizing factor (Factor XIII). Amer.J.Med. 44: 1 (1968).

2. Alami, S.Y.; Hampton, J.W.; Rage, G.J. and Speer, R.: The relationship of plasma fibrinogen (Factor I) level to fibrin stabilizing factor (Factor XIII) activity. Blood 31: 93 (1968).

3. Alexander, B.; Meyers, L.; Kenny, J.; Goldstern, R.; Gurewich, V. and Grinspoon, L.: Blood coagulation in pregnancy. Proconvertin and prothrombin, and the hypercoagulable state. New Engl.J. Med. 254: 358 (1956).

4. Ambrus, G.M.; Weintraub, D.H. and Ambrus, J.L.: Studies on hyaline membrane disease. III. Therapeutic trial of urokinase-activated human plasmin. Pediatrics 38: 231 (1966).

5. Ambrus, C.M.; Weintraub, D.H.; Dunphy, D.; Dowd, J.E.; Pickren, J.W.; Niswander, K.R. and Ambrus, J.L.: Studies on hyaline membrane disease. I. The fibrinolysin system in pathogenesis and therapy. Pediatrics 32: 10 (1963).

6. Ambrus, C.M.; Weintraub, D.H.; Niswander, K.R. and Ambrus, J.L.: Studies on hyaline membrane disease. II. The ontogeny of the fibrinolysin system. Pediatrics 35: 91 (1965).

7. Avery, M.E.: The lung and its disorders in the newborn infant; pp.110-111 (Saunders, Philadelphia/London 1964).

8. Beller, F. K.: Die Gerinnungsverhältnisse bei der Schwangeren und beim Neugeborenen (Barth, Leipzig 1957).

9. Bickford, A.F., Jr. and Sokolow, M.: Fibrinolysis as related to the urea solubility of fibrin. Thromb. Diath. haemorrh. 5: 480 (1961).

10. Cohen, M.M.; Weintraub, D.H. and LilienFELD, A. M.: The relationship of pulmonary hyaline membrane to certain factors in pregnancy and delivery. Pediatrics 26: 42 (1960).

11. Coopland, A.; Almjaersig, N. and Fletcher, A.P.: Reduction in plasma factor XIII (fibrin stabilizing factor) concentration during pregnancy. J. Lab. clin. Med. 73: 144 (1969).

12. Davidson, E. and Tomlin, S.: The levels of the plasma coagulation factors after trauma and childbirth. J.clin. Path. 16: 112 (1963).

13. Davis, M.E.; Russel, K.P. and Danforth, D. N.: Textbook of obstetrics and gynecology; p.641 (Hoeber, Harper and Row, New York/London 1966).

14. Davis, M. E.; Russel, K.P. and Danforth, D.N.: Textbook of obstetrics and gynecology; p. 644 (Hoeber, Harper and Row, New York/London 1966).
15. Egeberg, O.: Changes in the coagulation system following major surgical operations. Acta med. scand. 171: 679 (1962).

16. Fresh, J.W.; Ferguson, J.H. and Lewis, J.H.: Blood-clotting studies in parturient women and the newborn. Obstet. Gynec. 7: 117 (1956).

17. Gajl-Peczalska, K.: Plasma protein composition of hyaline membrane in the newborn as studied by immunofluorescence. Arch. Dis. Childh. 39: 226 (1964).

18. Giturn, B. and Graig, J.M.: The nature of the hyaline membrane in asphyxia of the newborn. Pediatrics 17: 64 (1956).

19. Good, R.A. and Papermaster, B.W.: Ontogeny and phylogeny of adaptive immunity. Adv. Immunol. 4: 1 (1964).

20. Haynes, D. M. : Premature separation of the placenta. Amer.J. Obstet. Gynec. 96: 660 (1966).

21. Hink, J.H., Jr. and McDonald, J. K.: Preparation of profibrinolysin-free fibrinogen and thrombin from human plasma. Nature, Lond. 194: 1080 (1962).

22. Jenny, J. und Abbuhl, A.: Gerinnungsphysiologische Untersuchungen. Gynaecologia 148: 347 (1959).

23. Johnson, B.L.: A review of coagulation defects in obstetrics. Brit. J. clin. Pract. 19: 3 (1965).

24. Kaulla, K. N. von; Kaulla, E. von and But"rerFIELD, J.: Fibrinolytic activity, thrombin inhibitor and kinetics of clot formation in premature infants with respiratory distress syndrome. Acta pediat. scand. 54: 587 (1965).

25. KünzeR, W.: Fötales Fibrinogen. II. Untersuchungen zur fibrinolytischen Resistenz des Nabelvenen-Fibrins. Klin.Wschr. 40: 478 (1962).

26. LAKr, K. and Lorand, L.: On the solubility of fibrin clots. Science 108: 280 (1948).

27. Loewy, A.G.; Dahlberg, A.; Dunathan, K.; KRIEL, R. and Wolfinger, H.L.: Fibrinase. II. Some physical properties. J. biol. Chem. 236: 2634 (1961).

28. Lorand, J.; Pilkington, T. R.E. and Lorand, L. : Inhibitors of fibrin cross-linking: Relevance for thrombolysis. Nature, Lond. 210: 1273 (1966).

29. Lorand, L. and Drckenman, R. G.: Assay method for the 'fibrin stabilizing factor'. Proc. Soc. exp. Biol., N.Y. 89: 45 (1955).

30. Lorand, L.; Downey, J.; Gotoh, T.; Jacobsen, A. and TokuRA, S.: The transpeptidase system which crosslinks fibrin by $\gamma$-glutamyl- $\varepsilon$-lysine bonds. Biochem. biophys. Res. Commun. 31: 222 (1968).

31. Lorand, L. and Jacobsen, A. : Studies on the polymerization of fibrin. The role of the globulin: fibrin stabilizing factor (FSF). J.biol.Chem. 230: 421 (1958). 
32. Lorand, L. and Konishi, K.: Activation of fibrin stabilizing factor by thrombin. Fed.Proc. 21: 62 (1962).

33. Markarian, M. and Jackson, J.J.: Comparison of the kinetics of clot formation, fibrinogen, fibrinolysis, and hematocrit in pregnant women and adults. Amer. J. Obstet. Gynec. 101: 593 (1968).

34. Markarian, M.; Lindley, A.; Jackson, J.J. and BANNON, A.: Coagulation factors in pregnant women and premature infants with and without the respiratory distress syndrome. Thromb. Diath. haemorrh. 17: 585 (1967).

35. MaCullough, J.A.; Creighton, L.E. and DeveREUX, W.P.: Antepartum hemorrhage. Obstet. Gynec. 31: 836 (1968).

36. Page, E.W.; King, E.B. and Merrill, J. A.: Abruptio placentae. Obstet. Gynec. 3: 385 (1954).

37. Perkins, H.A.: Postoperative coagulation defects. Anesthesiology 27: 456 (1966).

38. Phillips, L.L. and Skrodelis, V.: A comparison of the fibrinolytic enzyme system in maternal and umbilical-cord blood. Pediatrics 22: 715 (1958).

39. Quie, P.G. and Wannamaker, L.W.: The plasminogen-plasmin system of newborn infants. Amer.J. Dis. Child. 100: 836 (1960).

40. Ratnoff, O.D. and Donaldson, V.H.: Physiologic and pathologic effects of increased fibrinolytic activity in man. Amer. J. Cardiol. 6: 378 (1960).

41. Robbins, K. C.: A study on the conversion of fibrinogen to fibrin. Amer. J. Physiol. 142: 581 (1944).

42. Rogner, G.: Thrombelastographische Studien bei Frühgeborenen im ersten Lebensmonat. Z. Kinderheilk. 86: 565 (1962).

43. Samartzis, E.A. and Cook, G.D.: The relationship between age and fibrinolytic activity of serum. Acta pediat.scand. 49: 724 (1960).
44. Snedecor, G. and Gochran, W.: Statistical methods; 6th ed., pp.130-131 (Iowa State University Press, Ames, Iowa 1957).

45. TAlbert, L. M. and Langdeld, R.D.: Normal values of certain factors in the blood clotting mechanism in pregnancy. Amer. J. Obstet. Gynec. 90: 44 (1964).

46. Tsitouris, G.; Bellett, S.; Eilberg, R.; FeinBERG, L. and SANDBERG, H.: Effects of major surgery on plasmin-plasminogen inhibitors. Arch. intern. Med. 108: 208 (1961).

47. Tyler, H.M. and LACK, C.H.: A tissue fibrinstabilizing factor and fibrinolytic inhibition. Nature, Lond. 202: 1114 (1964).

48. Tyler, H. M. and LACK, C.H.: Studies on the relationship between fibrin-stabilizing factor, calcium and inhibition of fibrinolysis. Clin. Sci. 28: 527 (1965).

49. Wade-Evans, T.: The formation of pulmonary hyaline membranes in the newborn baby. Arch. Dis. Childh. 37: 470 (1962).

50. Obtained from the American Red Cross Blood Program through Squibb and Sons, New Brunswick, N.J.

51. We are grateful for the assistance of Mrs. C. Koepe, Mr. I. MINK and the following research nurses: Mrs. B. Striegel, Miss J.Eleczko, and Miss M. NORTHROP.

52. Aided by National Institute of Child Health and Development Grant no. HD 00249, National Heart Institute Grant no. HE 11591, National Cancer Institute Grants nos. Ca 07800 and 1-M01-FR-00262 and American Heart Association Grant no.67-900.

53. Requests for reprints should be addressed to: Clara M.Ambrus, M.D., Ph.D. Roswell Park Memorial Institute, Buffalo, NY 14203, USA. 54. Accepted for publication October 3, 1969. 